\title{
Ancient fungi found in deep-sea mud
}

\section{Discovery raises hopes that sea floor could yield previously unknown antibiotics.}

\section{BY RICHARD MONASTERSKY}

$\mathrm{R}$ esearchers have found evidence of fungi thriving far below the floor of the Pacific Ocean, in nutrient-starved sediments more than 100 million years old. The discovery has the potential to turn the brown muck of the sea floor into pure gold for biologists looking for alternative forms of life - and possibly for pharmaceutical companies seeking antibiotics to combat the growing problem of drug-resistant bacteria.

"This is adding a new family of potential drugs," says Brandi Reese, a biogeochemist at the University of Southern California in Los Angeles who studied the fungi, some of which belong to the genus Penicillium, the source of penicillin. Finding multicellular organisms in such a deprived environment "extends what we understand about the limits of life on the planet", says Heath Mills, a molecular geomicrobiologist at Texas A\&M University in College Station, who collaborated with Reese. They reported their results on 6 December at a meeting of the American Geophysical Union (AGU) in San Francisco, California.

To follow up on earlier reports of deep-sea fungi, Reese and her colleagues studied sediments pulled up from as deep as 127 metres below the sea floor during an expedition of the Integrated Ocean Drilling Program in the South Pacific in 2010. They searched the samples for fungal genetic material and found sequences from at least eight groups. The team succeeded in growing cultures of four of the fungi.

A decade ago, the only organisms known to live in deep layers of sediment were singlecelled - bacteria and archaea. Hints of fungi in sediments started emerging in 2005 , but just a handful of researchers are studying those sediment dwellers and the other fungi living in ocean water. "These things are ubiquitous and they're largely ignored," says Jennifer Biddle, a microbial ecologist at the University of Delaware in Lewes, who was among the first to culture fungi from sea-floor sediments (J. F. Biddle et al. Geobiology 3, 287-295; 2005).

Some biologists have been sceptical about

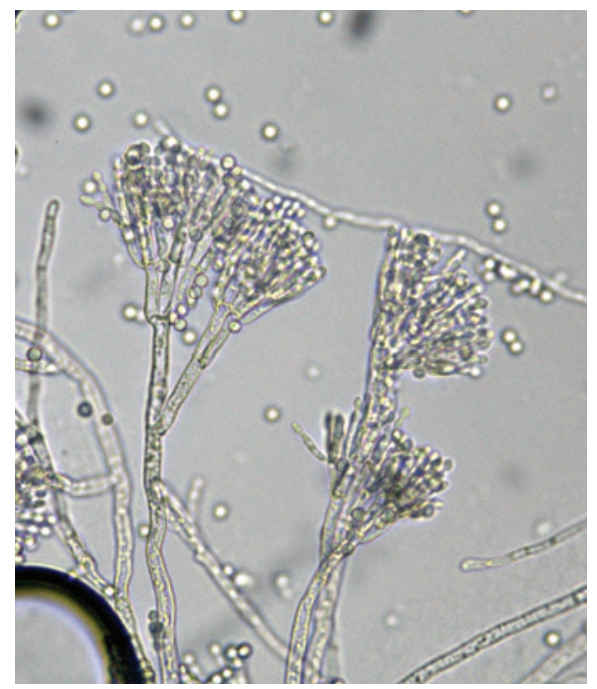

Penicillium fungi have been grown from sediments.

such reports, suggesting that the material might be the result of contamination - or inactive spores of surface fungi that became trapped in the muck. But Reese and her colleagues say that they took several steps to rule out contamination. Steven D'Hondt, who studies microbes in sediments at the University of Rhode Island in Narragansett, says that Reese's group and others are "accumulating a lot of evidence that there are fungi in the deep sediments".

And the material seems to be more than spores, says William Orsi, a molecular ecologist at the Woods Hole Oceanographic Institution in Massachusetts. Working with Biddle and Virginia Edgcomb, a microbiologist at Woods Hole, Orsi has studied deep-sea sediments from off the coast of Peru and detected bits of fungal messenger RNA that code for several proteins, including those involved in transporting ions and metals across membranes. This shows that the subsurface fungi are metabolically active, says Orsi, who presented the work at the AGU meeting.

Now that the evidence in favour of fungi in deep sediments is accumulating, "the pressing question is: what are they doing?" says Orsi. The sediments studied by Reese and her colleagues underlie the South Pacific Gyre "One of the most dead places on the planet," says Mills. The gyre is far from land, so few nutrients get there. Marine life is scarce and microbes in the surface sediments devour the scant organic matter that sinks to the bottom.

Mills thinks that the fungi might have a key role in the nutrient-starved deep ecosystem. Researchers have previously presumed that the organic matter left in sediments after millions of years is too difficult for most single-celled organisms to consume. But fungi are masters at breaking down tough organic molecules, says Mills, so they could be providing sources of food for microbes far below the sea floor.

The team says that it is not clear whether the fungi in the deepest sediments are more than 100 million years old; they might have colonized those layers by moving in from younger deposits. But if the fungi have been isolated for a long time, they may have evolved unusual biological defences against bacteria and could provide a source of useful antibiotics. "What if this is a new version of penicillin?” asks Mills. “That's one of the benefits of going to the deep biosphere." -

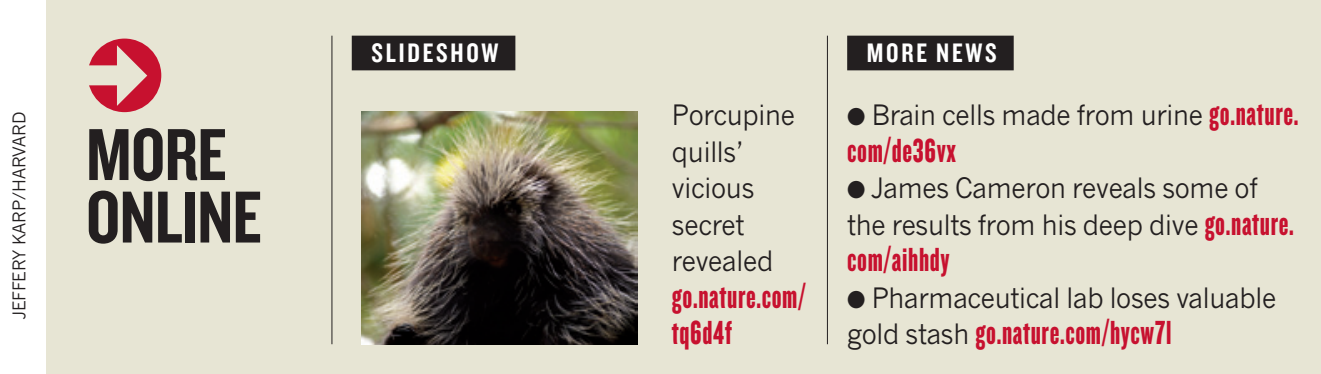

\section{VIDEO}

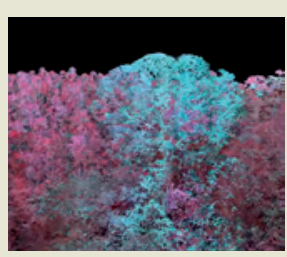

Airborne observatory reveals drought damage go.nature.com/ hbfgno 